\begin{tabular}{|c|c|}
\hline Title & Novel monoclonal antibodies that recognize both rat and mouse phosphatidy Iserine/prothrombin complexes \\
\hline Author(s) & $\begin{array}{l}\text { Kawakami, Tamihiro; Y oon, Sun Y oung; Takeuchi, Sora; Soma, Y oshinao; Kuroha, Sayo; Y oshida, Shigeru; Shida, } \\
\text { Haruki; Nakazawa, Daigo; Tomaru, Utano; Ishizu, A kihiro }\end{array}$ \\
\hline Citation & $\begin{array}{l}\text { Modern Rheumatology, 26(3), 470-471 } \\
\text { https://doi.org/10.3109/14397595.2015.1054090 }\end{array}$ \\
\hline Issue Date & $2016-05$ \\
\hline Doc URL & http:/hdl.handle.net/2115/65834 \\
\hline Rights & $\begin{array}{l}\text { This is an A cepeted Manuscript of an article published by Taylor \& Francis in Modern rheumatology on } 2016 \text { May, } \\
\text { avail able online: http://wwww.tandfonline.com/10.3109/14397595.2015.1054090. }\end{array}$ \\
\hline Type & article (author version) \\
\hline File Information & Mod Rheumatol 2015.pdf \\
\hline
\end{tabular}

Instructions for use 


\section{Novel monoclonal antibodies that recognize both rat and mouse phosphatidylserine/prothrombin complexes}

Short title: Novel monoclonal anti-PS/PT antibodies

Tamihiro Kawakami $^{1}$, Sun Young Yoon ${ }^{1}$, Sora Takeuchi ${ }^{1}$, Yoshinao Soma ${ }^{1}$, Sayo Kuroha ${ }^{2}$, Shigeru Yoshida ${ }^{3}$, Haruki Shida ${ }^{4}$, Daigo Nakazawa ${ }^{4}$, Utano Tomaru $^{5}$, and Akihiro Ishizu ${ }^{3}$

${ }^{1}$ Department of Dermatology, St. Marianna University School of Medicine, Kawasaki, Japan

${ }^{2}$ Graduate School of Health Sciences, Hokkaido University, Sapporo, Japan

${ }^{3}$ Faculty of Health Sciences, Hokkaido University, Sapporo, Japan

${ }^{4}$ Department of Internal Medicine II, Hokkaido University Graduate School of Medicine, Sapporo, Japan

${ }^{5}$ Department of Pathology, Hokkaido University Graduate School of Medicine, Sapporo, Japan

Correspondence to: Akihiro Ishizu, MD, $\mathrm{PhD}$, Faculty of Health Sciences, Hokkaido University, Kita-12, Nishi-5, Kita-ku, Sapporo 060-0812, Japan, Phone: 81-11-706-3385, Fax: 81-11-706-4916, E-mail: aishizu@med.hokudai.ac.jp 


\section{To the Editor,}

Anti-phospholipid syndrome (APS) is a prothrombotic disorder characterized by anti-phospholipid antibodies in the serum [1]. Anti-phospholipid antibodies recognize phospholipid-binding plasma proteins or phospholipid-protein complexes that include $\beta 2$ glycoprotein I ( $\beta 2 \mathrm{GPI}$ ) and prothrombin [2-5]. Recent studies have suggested that anti-phosphatidylserine/prothrombin complex antibody (anti-PS/PT antibody) is one of the most relevant autoantibodies to APS [6-9]. However, the precise mechanism of in vivo thrombogenesis induced by anti-PS/PT antibody remains unrevealed due to the limited number of monoclonal antibodies that recognize rodent PS/PT complexes.

We had established transgenic rats carrying the $e n v-p X$ gene of human $\mathrm{T}$ cell leukemia virus type I (HTLV-I) [10]. The pathogenic env-pX gene was introduced into the germline of WKAH rats under the control of the HTLV-I long terminal repeat promoter. Interestingly, these rats developed diverse collagen vascular diseases, including arthritis, sialo-/dacryoadenitis, thrombosis, myositis, and vasculitis, but not HTLV-I-associated lymphoid neoplasm. The onset of diseases was around 2 months after birth and the incidence at 6 months old was as follows approximately; arthritis: $80 \%$, sialo-/dacryoadenitis: $40 \%$, thrombosis: $30 \%$, myositis: $30 \%$, and vasculitis: 30\%. Various autoantibodies, including anti-nuclear, anti-DNA, and anti-cardiolipin/ $\beta 2$ GPI complex antibodies, were detected in the serum.

In this study, we determined the serum anti-PS/PT antibody levels in env-pX rats. Sera from thirteen 6-month-old morbid env-pX rats and twenty-five age-matched wild-type WKAH rats were subjected to a specific enzyme-linked immunosorbent assay. For this purpose, microtiter plates were first coated with phosphatidylserine (Sigma-Aldrich, St. Louis, MO) and then purified rat prothrombin (Oxford Biomedical Research, Rochester Hills, MI) was immobilized 
on the phosphatidylserine-coated plates in the calcium-containing buffer. Phosphatidylserine-coated plates without immobilization of prothrombin were used as the control plates. Anti-PS/PT antibody levels (OD value at $450 \mathrm{~nm}$ ) in the 1:101 diluted sera were significantly higher in env-pX rats than WKAH rats concerning both IgG (env-pX $0.094 \pm$ 0.094, WKAH $0.027 \pm 0.009, \mathrm{p}<0.0001)$ and $\mathrm{IgM}(\mathrm{env}-\mathrm{pX} 1.770 \pm 0.700$, WKAH $0.457 \pm$ $0.512, \mathrm{p}<0.0001)$ subclasses. Since no reactivity was detected in the wells without prothrombin, the sera did not react directly with phosphatidylserine. These findings indicate that env-pX rats are suitable models of APS.

Therefore, we generated monoclonal antibodies toward rat PS/PT complex using env-pX rats. For this purpose, we employed the conventional hybridoma methodology using the splenocytes or lymph node cells of 6-month-old morbid env-pX rats and mouse myeloma cells, P3U1. Finally, five hybridoma clones that produced anti-PS/PT monoclonal antibodies (Sp7-1, Sp7-11, Sp7-12, Sp7-14, and Ly3-135) were established. Isotyping revealed that they were all IgM class.

In order to determine the specificity of these antibodies, culture supernatants of hybridoma clones were added in microtiter plates coated with rat, mouse, and human PS/PT complexes, respectively. Mouse PS/PT plates were prepared similarly to rat PS/PT plates using purified mouse prothrombin (Oxford Biomedical Research). Phosphatidylserine-coated plates without immobilization of prothrombin were used as the control plates. Cross-reactivity with human PS/PT complex was examined using commercially available human PS/PT plates (Medical \& Biological Laboratories, Nagoya, Japan). As a result, all rat anti-PS/PT monoclonal antibodies showed high cross-reactivity with mouse PS/PT complex (Table 1). Since no reactivity was detected in the wells without prothrombin, the monoclonal antibodies did not react directly with phosphatidylserine. In contrast, these antibodies did not demonstrate cross-reactivity with human PS/PT complex. BLAST analysis revealed that the amino acid homology between rat 
prothrombin and mouse prothrombin is $94 \%$, whereas between rat prothrombin and human prothrombin, it is $80 \%$. Our results are consistent with this evidence.

Among the five hybridoma clones, Sp7-11 had shown the most vigorous growth in vitro. Thus, we employed this clone for mass production of rat anti-PS/PT monoclonal antibody. By injection of $\mathrm{Sp7}-11$ cells into the intraperitoneal cavity of three BALB/c nude mice (1x10 $/$ mouse), $7 \mathrm{ml}$ ascites containing $5 \mathrm{mg} / \mathrm{ml}$ of rat $\mathrm{IgM}$ was obtained. For the following experiments, affinity-purified rat anti-PS/PT IgM monoclonal antibody (Sp7-11) was used.

Next, in order to determine the thrombogenic potential of the rat anti-PS/PT monoclonal antibodies in vivo, young pre-morbid env-pX rats (5-week-old, female, $\mathrm{n}=5$ ) were given intravenous injection of the affinity-purified Sp7-11 $(200 \mu \mathrm{g} / 500 \mu \mathrm{l} / \mathrm{rat})$ at day 0 and day 7 , and then killed for histological examinations at day 14. Thrombosis developed in 2 of 5 rats given intravenous injection of Sp7-11 at 7 weeks of age (Figures 1A-1D). The affected vessels included the pulmonary vein and artery, and a small arteriole in the subcutaneous connective tissue. In our experience, male rats are more susceptible than female rats in this model and spontaneous development of diseases, including thrombosis, has be seldom seen in female env-pX rats at this age (7 weeks old). In consistent with this, no thrombosis occurred in age- and sex-matched env-pX rats similarly given control rat IgM (eBioscience, Tokyo, Japan) (n=3, Figures $1 \mathrm{E}$ and $1 \mathrm{~F})$. These findings seem promising but are insufficient; hence, we are going to confirm through further investigations in order to submit as relevant results in the future.

In this letter, we introduce the establishment of novel monoclonal antibodies toward both rat and mouse PS/PT complexes. Although further studies are required to ensure if the anti-PS/PT monoclonal antibodies would induce thrombosis in rats and mice, they could be useful tools for investigating the pathogenesis of APS, not only in vitro assay but also in vivo assay using rodent 
models.

\section{Acknowledgements}

This work was supported by grants from the Scientific Research Fund of the Ministry of Education, Science, Sports and Culture, of Japan (No. 20591356 and No. 23591658). The authors would like to thank Professor Tatsuya Atsumi, Department of Internal Medicine II, Hokkaido University Graduate School of Medicine (Sapporo, Japan) for critical reading of this manuscript.

\section{Conflict of Interest}

None. 


\section{References}

1. Gezer S. Antiphospholipid syndrome. Dis Mon 2003;49(12): 696-741.

2. Galli M, Comfurius P, Maassen C, Hemker HC, de Baets MH, van Breda-Vriesman PJ, et al. Anticardiolipin (ACA) directed not to cardiolipin but to a plasma protein cofactor. Lancet 1990;335(8705):1544-7.

3. Matsuura E, Igarashi Y, Fujimoto M, Ichikawa K. Anticardiolipin cofactor(s) and differential diagnosis of autoimmune disease. Lancet 1990;336(8708):177-8.

4. Bevers EM, Galli M, Barbui T, Comfurius P, Zwaal RF. Lupus anticoagulant IgG's (LA) are not directed to phospholipids only, but to a complex of lipid-bound human prothrombin. Thromb Haemost. 1991;66(6):629-32.

5. Atsumi T, Ieko M, Bertolaccini ML, Ichikawa K, Tsutsumi A, Matsuura E, et al. Association of autoantibodies against the phosphatidylserine-prothrombin complex with manifestations of the antiphospholipid syndrome and with the presence of lupus anticoagulant. Arthritis Rheum 2000;43(9):1982-93.

6. Amengual O, Atsumi T, Koike T. Specificities, properties, and clinical significance of antiprothrombin antibodies. Arthritis Rheum 2003;48(4):886-95.

7. Vlagea AD, Gil A, Cuesta MV, Arribas F, Diez J, Lavilla P, et al. Antiphosphatidylserine/prothrombin antibodies (aPS/PT) as potential markers of antiphospholipid syndrome. Clin Appl Thromb Hemost 2012;19(3):289-96.

8. Hoxha A, Ruffatti A, Tonello M, Bontadi A, Salvan E, Banzato A, et al. Antiphosphatidylserine/prothrombin antibodies in primary antiphospholipid syndrome. Lupus 2012;21(7):787-9.

9. Pregnolato F, Chighizola CB, Encabo S, Shums Z, Norman GL, Tripodi A, et al. Anti-phosphatidylserine/prothrombin antibodies: an additional diagnostic marker for APS? Immunol Res 2013;56(2-3):432-8. 
10. Yamazaki H, Ikeda H, Ishizu A, Nakamaru Y, Sugaya T, Kikuchi K, et al. A wide spectrum of collagen vascular and autoimmune diseases in transgenic rats carrying the env-pX gene of human T lymphocyte virus type I. Int Immunol 1997;9(2):339-46. 
Table 1. Reactivity of anti-PS/PT monoclonal antibodies

\begin{tabular}{lccc}
\hline \multirow{2}{*}{ Sample } & \multicolumn{3}{c}{ OD $(450 \mathrm{~nm})$} \\
\cline { 2 - 4 } & Rat PS/PT complex & Mouse PS/PT complex & Human PS/PT complex \\
\hline Sp7-1 & 1.979 & 1.824 & 0.036 \\
Sp7-11 & 1.937 & 1.836 & 0.033 \\
Sp7-12 & 1.953 & 1.833 & 0.036 \\
Sp7-14 & 1.966 & 1.847 & 0.035 \\
Ly3-135 & 1.912 & 1.800 & 0.092 \\
PBS & 0.010 & 0.010 & ND \\
Human standard serum* & 0.192 & ND & 1.336 \\
\hline
\end{tabular}

*Serum from a patient with APS (1:101 dilution)

ND: not done 


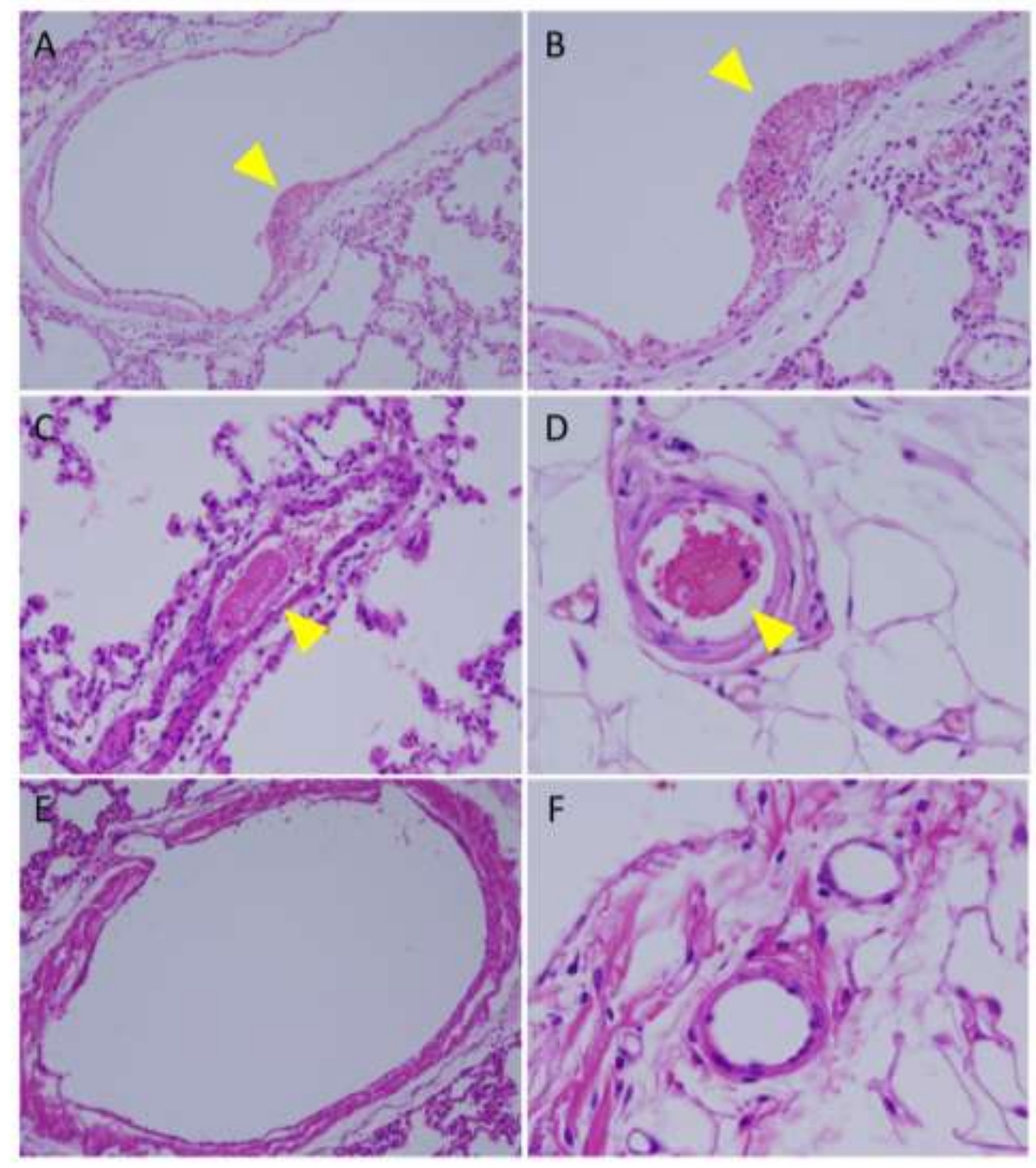

\section{Figure 1. Thrombogenic potential of rat anti-PS/PT monoclonal antibodies}

Young pre-morbid env-pX rats (5-week-old, female, $\mathrm{n}=5$ ) were given intravenous injection of

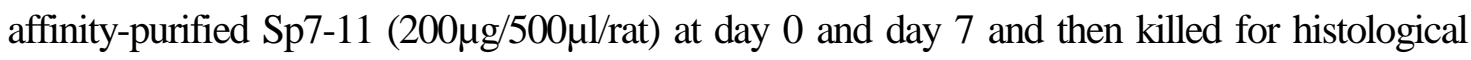
examinations at day 14 . Thrombi observed in the pulmonary vein (A, original magnification: $\times 100$; B, original magnification: $\times 200)$, pulmonary artery $(C$, original magnification: $\times 200)$, and subcutaneous arteriole $(\mathrm{D}$, original magnification: $\times 400)$ (Yellow arrow heads). No thrombosis occurred in age- and sex-matched env-pX rats similarly given control $\operatorname{IgM}(n=3)$. (E) Pulmonary vein (original magnification: $\times 100$ ). $(F)$ Subcutaneous arteriole (original magnification: $\times 400$ ). 